\title{
HARLEM TODOS LOS DIAS: EL EXILIO DEL NOMBRE/EL NOMBRE DEL EXILIO
}

\author{
POR \\ EDUARDO C. BÉJAR \\ Middlebury College
}

Poi disse a me: "Elli stessi s'accusa; questi è Nembrotto per lo cui mal coto pur un linguaggio nel mondo non s'usa.

"Inferno", XXXI (76-78).

No serfa desacertado afirmar que en el contexto de las letras hispanoamericanas del siglo en curso, es la narrativa puertorriqueña la primera en haber regularmente incorporado el locus de la situación exílica al repertorio de su escritura. La considerable emigración de la Isla a partir de la Segunda Guerra Mundial como única respuesta a la agobiante situación socio-económica de unagran parte del pueblo fue inmediatamente textualizada por los escritores de la llamada generación del cuarenta, ${ }^{1}$ en cuya labor se destaca Emilio Díaz Valcárcel con sus novelas Figuraciones en el mes de marzo (1972) y Harlem todos los días (1978). ${ }^{2}$ En ambos textos los protagonistas se encuentran viviendo en suelo ajeno, Madrid y Nueva York respectivamente: el exilio en la tierra castellana aparece en el primero como complemento de una narrativa fragmentada y colecticia (novela álbum) para la representación de un sujeto alienado; la situación de expatriación neoyorquina presentada en el segundo aparece como la anécdota central que impulsa la trama y constituye, por lo tanto, la condición de posibilidad del relato mismo. El cuerpo de la narrativa

\footnotetext{
${ }^{1}$ Véanse como ejemplos, El hombre en la calle (1948) y Paisa (1950) de José Luis González; Trópico de Manhattan (1951) de Guillermo Cotto-Thorner; La carreta (1951) de René Marqués; y Spiks (1956) de Pedro Juan Soto. Un sector de la crítica y el mismo Soto opinan que este grupo debe ser considerado como la generación del cincuenta.

${ }^{2}$ La crítica concuerda en considerar a Díaz Valcárcel, y en especial su novela Figuraciones en el mes de marzo como el escritor y texto que rompen definitivamente con los modos narrativos más tradicionales de la generación anterior, y que permiten engarzar a la literatura puertorriqueña con la narrativa del "boom". Léanse a este respecto el artículo de Juan Martínez Capo, "La escena literaria", Puerto Rico llustrado (12 de noviembre, 1972), y el de Estelle Irizarry, "Los hechos y la cultura en los EE.UU". Nivel. Gaceta de cultura 131 (México, 30 de noviembre, 1973).
} 
puertorriqueña que se extiende hasta estas dos novelas de Díaz Valcárcel manifiesta que el fenómeno exílico ha estado efectuandoel acto de literaturización de la expatriación con un rico arsenal de integración que va desde una inicial y simple mención referencial hasta una participación ontológica con la materia narrativa misma.

Esta relación fecunda entre exilio y literatura - tan antigua como Ulises y tan imbricada como Joyce - ha venido a ocupar en el momento actual un lugar de concurrido interés crítico. La intensidad de tal incidencia puede explicarse, en gran medida, por la toma de conciencia de la literatura como acto crítico de desenajenamiento facilitada por la nueva teoría de la escritura ${ }^{3}$ Es decir, por el reconocimiento del potencial disruptor que tiene el acto literario sobre los discursos homogeneizantes y modelos históricos normativos que conforman la hegemonía del sistema social imperante, término éste entendido en el sentido más amplio de consenso de actuación social, cuyo mantenimiento y poder se basan, como señalara Gramsci, en una singular concepción político-económica y cultural tácitamente aceptada por todos los componentes como la de mayor operatividad. ${ }^{4}$ Puesto que la literatura sobre la experiencia exílica es fundamentalmente un hostigante comentario a las condiciones socio-ideológicas y económicas causantes de ese desarraigo, sus registros temáticos, retóricos y lingüísticos pueden ser propuestos como materiales idóneos para esta funcionalidad crítica de la escritura.

A este respecto Paul Mie ha recientemente derivado del testimonio literario sobre el exilio - tanto externo como interno- de la España franquista un modelo de exolalia, o literatura exílica, apto de ser extendido al agudo desplazamiento panhispánico intimidado hoy día por toda actuación ideológica exclusivista, indiferente de su sesgo político. ${ }^{5}$ Yaún más, como mapa de diferentes discursos periféricos que buscan escapar de la normalización regida por un discurso oficial, este modelo peninsular es pertinente a todas las sociedades exilogénicas. La tipología propuesta por llie resume las expresiones literarias del exilio a cinco variantes modales: 1) el testimonio del éxodo inicial, 2) las expresiones regionales marginalizadas, 3) la literatura directamente

${ }^{3}$ Obligada es naturalmente la referencia al pensamiento de Barthes sobre una escritura "libre y utópica" como proyecto crítico en la sociedad. Le degré zéro de l'écriture (Paris: Editions Gonthier, 1971).

4 Este concepto gramsciano se opone al más limitado de imposición política dentro de la cual actúan focos conscientes de oposición. Para un estudio del pensamiento de Antonio Gramsci, véase Walter L. Adamson, Hegemony and Revolution (Berkeley: University of California Press, 1980).

$\checkmark$ "Exolalia and Dictatorship: The Tongues of Hispanic Exile". Fascismo y experiencia literaria: reflexiones para una recanonización, ed. Hernán Vidal (Minnesota: Society for the Study of Contemporary Hispanic and Lusophone Revolutionary Literatures, 1985) 222-52. 
comprometida, 4) la variante fantástica, y 5) la literatura antirreferencial sustraída de la historia. ${ }^{6}$

Esta tipología de exolalia, sin embargo, ha dejado de incluir una expresión fundamental en el cuadro modal de escrituras exilicas. Me refiero a la variante conformada por aquellos discursos que manifiestan el fenómeno de lenguas en contacto, es decir, la expresión literaria que trabaja con la poliglosia y la pluralidad cultural. Su presencia en el campo de la literatura hispánica del exilio se ha hecho bien evidente a raíz del incrementado éxodo de grupos hispánicos hacia los Estados Unidos en los últimos decenios, y de su consolidación como fuerza político-cultural. El rasgo común a estos discursos se halla, naturalmente, en el manejo simultáneo o mixto de dos o más códigos lingüísticos y culturales, junto a la concomitante ideología de grupo periférico que trata de reafirmar su identidad híbrida en el homogéneo texto cultural que sirve de receptor. No se trata ya ni de la problemática de la pureza ni del soslayo de la censura, comunes a las variantes de llie, sino de una inscripción transgresiva al reunir hablas y códigos socio-culturales mantenidos en mutua exclusión.

Dentro de este tipo de discurso exílico, el texto novelístico Harlem todos los días $^{7}$ de Díaz Valcárcel constituye una instancia narrativa paradigmática, cuanto que la estrategia discursiva empleada de contaminación lingứística y cultural señala al lenguaje como lugar crítico efectivizante de la disrupción hegemónica, y no como mero ornamento a la temática del desarraigo. De esta manera, es el escenario del lenguaje en proceso de hibridización donde Díaz Valcárcel libra una batalla de triple frente que sobredetermina la significación textual: el primero continúa la línea tradicional en la literatura puertorriqueña de denuncia ante la situación socio-económica que problematiza la identidad insular pero extendiendo esta situación particular de ontología nacional a un horizonte universal, al configurar el múltiple encuentro lingüístico y cultural

\footnotetext{
${ }^{6}$ Según Ilie, la primera variante, caracterizada por un fuerte mimetismo moralizante, se erige como protectora de la honestidad nacional y como repositoria auténtica de una lengua no adulterada por la ideologia dominante. Las expresiones paracultares del exilio interno conforman la segunda variante, mientras que la tercera se refiere explícitamente a la literatura testimonial política que busca la imagen "pura" de la realidad nacional más que la pureza nominalista de la primera. El lenguaje alucinatorio y criptográfico de temas fantásticos trata de evadir los límites de la censura mientras que las expresiones "grafocéntricas" afirman la autonomia y reversibilidad del lenguaje con lo que se sustraen del compromiso histórico. Es curioso el hecho de que esta tipología de llie sobre los modos exílicos de disensión establece una figuración que paraleliza la transformación de la literatura desde el representacionalismo decimonónico hasta el presente postmoderno: un primer momento de transparencia del significante, otro intermedio de ambigüedad translúcida y uno final de opacidad material del signo lingǘstico.

${ }^{7}$ Emilio Díaz Valcárcel, Harlem todos los dias (San Juan: Ediciones Huracán, 1978). En adelante, todas las citas son de esta edición.
} 
del archivo babélico por excelencia que es Nueva York; ${ }^{8}$ el segundo nos advierte sobre la dimensión política del lenguaje como medio performativo donde se estabilizan, sin resolverse, las luchas entre intereses sociales opuestos, y se legitimiza el discurso normativo de poder de la clase dominante; ${ }^{9}$ y el tercero convierte la representación de la poliglosia del exilio en comentario metalingüístico contra la narrativa de lenguaje acabado, al contaminar la pureza de las formas morfosintácticas, y al dialogizar tanto a la voz narrativa como centro de enunciación como a la instancia autorial como punto de originación..$^{10}$ Desde esta triple óptica, una lectura de las estrategias narrativas y retóricas elaboradas alrededor del personaje central de la novela justificará la propuesta de Harlem todos los días como texto paradigma en que la exoglosia polifónica sirve como agente desmantelador de la red hegemónica elaborada a través del lenguaje y de sus sistemas de representación.

El comienzo del relato presenta a Gerardo, jíbaro puertorriqueño recién llegado al exilio de Nueva York en busca de trabajo. Tanto su físico como su capacidad imaginativa dibujan el emblema de un ontos borinqueño dominado por una intención hegemónica monovalente. Gerardo es pelirrojo y de ojos azules, fácil de ser identificado como de pureza nórdica; su temperamento de "zángano" tímido y "pendejo" perezoso es naturalmente compensado por el machismo de su probidad fálica; $y$, de mayor implicación, su pensamiento está caracterizado por una notoria limitación de creatividad, situación comprobada por su constante refugio en el descanso de los lugares comunes lingüísticos, especialmente el obtenido "bajo la fronda de los refranes" (106). Estos, como sintagmas fijos e irreversibles no entran en la combinatoria lingüística libre y creadora que constituye la actividad fenomenológica del habla. Partiendo de las anotaciones de Bakhtin sobre el discurso épico autoritario-cuyo curso crítico produce esta lectura-el constante recurso a esta unidad cerrada de la lengua emblematiza a Gerardo como víctima y agencia a la vez de la percepción acabada y antidialógica encontrada en el discurso monolítico de la épica y de los otros

\footnotetext{
${ }^{8}$ El sentido de archivo, según Foucault, de juego de relaciones que rige la aparición de los eventos (enunciados) como acontecimientos singulares y no como simple acumulación, acompaña mi lectura de este encuentro plural. Véase L'archéologie du savoir (Paris: Editions Gallimard, 1969) 169-70.

${ }^{9}$ De nuevo, la correspondencia con el proyecto que Foucault anunciara en su L'ordre $d u$ discours (Paris: Editions Gallimard, 1971) es evidente. Por otra parte, la observación de Terry Eagleton de que el momento de consolidación de la "nación-estado" es un momento en el que la hegemonía de una "clase-nacional" se refleja en la coherencia lingǘstica esencial a su aparato de poder integrativo y centralizante, resume el pensamiento crítico elaborado con respecto a la relación estructural entre lengu aje y hegemonía. En Criticism and Ideology (London: Verso, 1976) 55.

${ }^{10}$ En esta triple batalla, Díaz Valcárcel responde asimismo a la necesidad, por él mismo señalada, de ir más allá del "tema" (la búsqueda de la identidad) de la literatura puertorriqueña. "Entrevista". Hispamérica 25-26 (1980) 61-68.
} 
géneros "altos" de la literatura. ${ }^{11}$ Según Bakhtin, estas manifestaciones literarias construyen una representación del mundo basada en un distanciamiento idealizante y absoluto con el objeto enfocado, el que se desplaza al campo de la memoria y se funde con relaciones espacio-temporales jerárquicamente determinadas. Dentro de estas expresiones, por lo tanto, se resuelven las tensiones de la experiencia, configurando una imagen inmutable y conclusa tanto de la realidad como del sujeto. Habiéndose limitado el trabajo de la palabra a la consagración del evento, la visión épica no entra en la esfera revalorativa e incompleta del presente en creación. Su discurso resultante es, por consiguiente, el lenguaje de la tradición y la oficialidad autoritaria, de la exposición patriarcal y monoglósica. ${ }^{12}$ Cuanto que todo el decir-saber de Gerardo se repliega en "un conjunto de sensaciones, de respuestas mecánicas" (65) y en un "Genio y figura hasta la sepultura, mi pana" que "su abuela había sembrado en su meollo y que resumía un mundo de sabiduría arrastrada durante quién sabe cuántos siglos" (62), el campo de su hacer-crear se limita a la continuación de los semas estériles con los que se persevera la inmobilidad de los aparatos ideológicos establecidos como organismos de control. ${ }^{13}$

La llegada de Gerardo a la metrópolis políglota y multicultural de Nueva York lo inserta sin preámbulo en un "mundo que se le trenza de manera poco discursiva" (11). Este texto plural, que solamente puede explicar con las palabras "mogolla" y "burundanga", lo incita a una apertura en su pensar acabado, actividad harto desquiciante "sobre todo porque empieza a ensamblarimágenes arbitrarias y en vez de desear una cama por ejemplo piensa en una bicicleta, cosa que lo agota sensiblemente" (11). Como respuesta inmediatizada a la complejidad de ese entorno galimático y policéntrico, se aferra, naturalmente, a los proverbios y a las "sombras elusivas y simples" (11) que son las imágenes estereotipadas de su soleada ínsula. Estos, en su función lingüística naturalizante lo sostienen dentro de la comprensibilidad de los códigos en rigor. Su afán inconsciente de status quo está, no obstante, destinado a un desmoronamiento por la fuerza subversiva del abigarramiento glósico y étnico del exilio, alegorizada en la mulata figura del sapientísimo Aleluya, remedo caribeño del Virgilio dantesco, quien lo recibe en su llegada a la Urbe y le sirve de guía en sus cíclicos recorridos por las calles del inmenso conglomerado.

${ }^{11}$ M. M. Bakhtin, The Dialogic Imagination, ed. M. Holquist (Austin: The University of Texas Press, 1981) 3-40.

12 Cito de Bakhtin:

This idealization of the past in high genres has something of an official air. All external expressions of the dominant force and truth (the expression of everything conclusive) were formulated in the valorized-hierarchical category of the past, in a distanced and distant image (everything from gesture and clothing to literary style, for all are symbols of authority) 20 .

${ }^{13}$ Véase Louis Althusser, "Ideologie et appareils ideologiques d'Etat". Positions (Paris: Editions Sociales, 1976) 81-137. La 6ptica marxista de Althusser considera como Aparatos Ideológicos del Estado una serie de instituciones especializadas como las escolares, religiosas, familiares, juridicas, sindicales, informativas, etc. 
La figura cromática de Aleluya se adelanta en el relato como signo de apostolado militante de la pluralidad (21) en el que se incorporan lo material y lo divino (16), la religión y la política (17) sin exclusión mutua. En su funcionamiento políglota - habla lenguas tan apartadas como el guaraní, el yiddish y el judeo-español - se resume la presencia de un ámbito exúlico que socava los principios de asimilación con que toda sociedad de serialización construye su hegemonía. ${ }^{14}$ De manera similar, el marcado hieratismo de su enorme erudición filosófica y filológica - ha leído repetidas veces textos como la Biblia, L'etre et le néant, Gli eroici furori y Kunst und Kultur der Vorzeit (91)se convierte en praxis descentralizante, al estar atravesada por el trabajo de mejoramiento de los grupos marginalizados. Leemos que a su enorme capacidad noética se le adjunta el entusiasmo por "la sencillez y simpleza de sus amigos" del Barrio (19), lugar donde "se habla con franqueza" (19) y donde se encuentran espíritus formados por "viejas filosofías no codificadas por los sabihondos occidentales de siempre" (171). Participando plenamente del "embrujo" étnicolingüístico de la Babel contemporánea, su activo mesianismo antihegemónico se nutre de la polifonía semioglósica transmitida por los "reputados ruidos neoyorkinos" (79) de la "Calle por antonomasia" (191). Este emplazamiento plural de Aleluya como cicerón neoyorquino lo convierte en agencia virgiliana que conduce a la persona stolta del jíbaro-burgués en un proceso de aprendizaje desmitificador. Con funcióninversaal discurso dantesco que sirve de intertexto, ${ }^{15}$ la dimensión disruptiva del hablar de Aleluya es una anomalía discursiva que confunde radicalmente el fácil monologismo de Gerardo:

\footnotetext{
14 La relación de fricción entre la voluntad de sometimiento de la cultura dominante y la de sobrevivencia de las culturas periféricas en los Estados Unidos ha sido estudiada en base a la dinámica de la asimilación por Milton M. Gordon en Assimilation in American Life (New York: Oxford University Press, 1964).

${ }^{15}$ Alberto Asor Rosa ha señalado que el proyecto inicial de Dante desplegado en De vulgari eloquentia consiste en la fijación de una "gramática" común a las hablas vulgares (sermo humilis) de la Italia medieval por medio de la cual resistir la historicidad e impermanencia de la palabra:

Con el termine 'gramatica' egli intende general mente non una lingua a sé, ma un livellopossibile di qualsiasi lingua: piú precisamente, quel livello in cui la strutturazione e la regolazione dei 'caratteri' propi di quella lingua hanno finito per prevalere sulla spontaneitz", en "La fondazione del laicon, Letteratura italiana V (Torino: Giulio Einaudi editori, 1986) 39.

Por otra parte, Thomas Green señala en su análisis del Renacimiento literario, The Light in Troy (New Haven: Yale University Press, 1982), que esta manifiesta ansiedad sobre la mutabilidad lingürstica está en La divina commedia asociada sinecdóquicamente a la contingencia de toda construcción humana, con lo que anticipa la quimera del humanismo renacentista de cimentar los accidentes del uso con una forma autoritaria universal. De esta manera se explica el interés de Dante de arrojar una dimensión sagrada, profética y por lo tanto trascendente, al dolce stil novo de su comedia poética, legitimizando a la vez el uso dialectal toscano. Este visionario estilo épico serviría más adelante como una justificación de la estandarización del toscano como medio lingürstico oficial de Italia.
} 
Otra vez Gerardo temio una emboscada dialéctica, cierta manipulación urdida sin evidente malicia. Le tendían una trampa. Le van tejiendo una telaraña de palabras. Le construyen taimadamente un foso cubierto con hojaspalabras (75).

El escándalo epistemológico propiciado por Aleluya halla su correlato en la espesa y heteroclítica "burundanga" semiótica y lingüística de Manhattan. La Urbe textualizada es ámbito de convergencia donde los intereses del signo del FIRST NATIONAL CITY BANK cohabitan con las zonas de escritura del CHINA GARDEN-TZECHWAN FOODS, de la BODEGA LA ISLA y del RESTAURANTE QUISQUEYA (41); la verticalidad paradigmática del listado DELICATESSEN, BOTÁNICA, DRUGSTORE, LIQUOR STORE Y COMIDAS CRIOLLAS (123) convoca el entrecruzado de arsenales léxicos disyuntivos; y donde el "simetrísimo neotemplo" plenipotenciario del ROCKEFELLER CENTER convive con el MESÓN DEL QUIJOTE, recinto connotador de voz más abierta (154). Otro lugar de encuentro y restauración, el MESÓN DEL CORDERO, con su "imaginativa paella heterodoxa" de "todo bicho terrestre, del subsuelo, de agua dulce, marinoo volandero" (130) y su des-concierto estructural de "babélica concentración de acentos y lenguas extrañas" (131), se lee como microcosmos de la efervescencia intercultural que dinamiza todos los días de Harlem/Harlem. Esta conjura sígnica del exilio neoyorquino que entorna a Gerardo es el resultado del archivo lingüístico de una satura de personajes expatriados que por un lado interseminizan la privacidad de sus lenguajes y por otro contaminan el espacio sonoro del homogéneo ámbito arquitectónico de "cajones geométrica mecánicamente alineados" (36).

La pluralidad de códigos lingüísticos aportados por la madeja de exiliados es a su vez transcrita de manera paródica en tanto que degradación de cualquier reclamo narrativo de seriedad y jerarquía. Así, la lectura del deambular de Gerardo en el espaciocrítico de Harlem está concurrida porinstancias discursivas donde se elaboran humorísticamente parodias dialectales y falsos koine que marcan la estrategia irrespetuosa del narrador ante la propiedad del código en cuestión:

El cubano Fulgencio Guerra dijo habaneramente que esta ciudad está dura, mi socio, la cosa está que adde pa los que trabajan fuette y pa los de cobbata ... El brasileño Bragạ da Cuhna comentó meu speranz son cançoens do Brasil, fina dansa carioca na Minas Gerais ... Te habés salvado, ché, interviene Macedonio, si es que sos músico, los morlacos a patadas, pibe, ... Glauco Hermosillo dijo que en Ecuador la cosa pior que en ningún lao, cholos y sambos cunsha huairapamushcas United Fruit ... El japonés Asho Jodoka interviene tajante, hirohitamente Amérika taka ga y Spiros Octopoulos, sospechando que sus amigos apenas podrian entenderle, pronunció cuidadosamente cada logo, Aristodo kulos América, yatti maginas restoppo, kalamaris scasayatis marathonoupolos kostagravas ... y el joven de ojos azules y pelo rojo crespo dice en Puelto Rico pasa igual, es que tos nos dejamos cogel de surumah. Qui Tao sentencia, sa lau, sin pan ta lon. Nikko jon, espeta Jodoka ... ¡Pucha!, exclama Macedonio, mirá la hora que son, ché. ¿Dónde vivís vos? Le sin ton, dice el chino 
Qui Tao. Y Jodoka comenta señalando a lo lejos yokami napata, tamikasa michiko (28-9).

Frente a tal entrecruzamiento lingüístico, el monoglósico Gerardo, quien desde el comienzo de su presencia textual en el "tensamente amistoso" (11) bar del negro sureño Dutch había demostrado una inclinación hacia el bilingüismo con su "okay" de despedida, experimenta "un desvanecimiento correoso, de guanábana a punto de caerse del palo" (29). Poco a poco su resistencia insular se va desplazando hacia un "cariño por la ciudad", por "la gente como él, todos con sus sueños como fardos vacios, shit, man, se le ha pegado, y por eso la ciudad es bonita, Broadway se está corroyendo, tan amplia, levantada como una fachada brillante contra la brisa, a punto de venirse abajo; Broadway marcada ya para siempre" (95). Este mundo de "condimentos transoceánicos" (145), al que el dantesco Aleluya lo introduce en paulatino aprendizaje contaminante (209), constituye la fuerza de hibridización que cava en la unidad subjetiva de Gerardo. Finalmente, con la cópula carnal y lingüística de la ya híbrida Catalina/Cathy/Caty, novorriqueña de "dulce y macizo cuerpo nutrido de todas las esencias neoyorquinas" (145), el relato alegoriza la pérdida del himen ideológico y glósico responsable de la virginidad monológica del pelirrojo jíbaro:

Y entonces sus cuerpos se acercaron hasta rozarse tocándose en sus puntos calientes la mar de sensibles: ... dos cuerpos bien recortados en medio de un viejo atardecer de Harlem, sólidos, macizos, quemándose en un avanzado septiembre de calles ateridas con el más ruidoso y conversado y palabrero silencio jamás experimentado por boricua amante alguno, las palabras se encendían en sus cerebros nobles jóvenes y cobraban una densidad cegadora iluminaban recónditos intersticios y luego caían apagándose como estrellas fugaces mientras continuamente iban surgiendo palabras que repetían el proceso anterior y se mezclaban unas con otras, se superponían y competían con brillantez, parecía que cada uno sostuviera un certamen de fuegos de artificio deslumbrantes $\sin$ palabras sonoras se dijo pero formadas por rasgos luminosos se dijo (100-1).

El exilio neoyorquino apoyado en el modelo antimaniqueísta de Aleluya, en el protocolo subversivo que lo acompaña, y en la mixta Caty puede ser leído entonces como texto lingüístico-cultural refractario por medio del cual Gerardo enturbia "la suavidad del barrio pueblerino" (191), es decir, su visión singular del mundo. El proceso de incorporación de lo heterogéneo, connotado como período gestativo de nueve meses por el referente temporal de la vida de Gerardo en la Urbe desde el comienzo hasta el fin del relato, es una entrada en contacto con el Otro que no sólo exilia a Gerardo de su propiedad nominal al convertirlo en Gerald/Gerry, sino que en la relación con Caty gesta a un neo-novorriqueño, Geraldito, doble dialogizado del Gerardito dejado en la ínsula y metáfora de su nuevo ser bilingüe. Tal desdoblamiento del nombre original, entendido éste como fijación cultural monolítica y como externalización acabada de la persona, es una disrupción explícita de la unidimensionalidad del sujeto que, como hemos 
mencionado, Bakhtin considera el centro autoritario de la imagen épica. ${ }^{16}$ Una vez incorporada la otredad del discurso incoalescente de Caty, la agencia dialogizada de Gerardo/Gerald/Gerry está capacitada para asumir al final del relato el espacio simbólico que queda vacante con la desaparición del subversivo superintendente del edificio en el que reside Gerardo, el siciliano Dino Calabrio, cuya "originalmente mirada nítida meridional" había sido igualmente "enturbiada" por "el polvo de la ciudad" (105): el relato abre así un nuevo ciclo de descentralización en la dinámica interlingüústica de Harlem todos los días al desplazar la función actancial crítica de un foco de disensión social ya demarcado, a otro en vía de importación.

Esta representación de la potencialidad disruptora del sujeto exiliado como entidad trans-étnica se halla tematizada en la naturaleza equívoca del protocolo de "actores" ${ }^{17}$ que colaboran silenciosamente en el proyecto de acción revolucionaria directa. El nombre de Aleluya sirve de velo léxico al enigmático Alberto Pérez, mezcla mulata borinqueña y santotomasina del sur de Puerto Rico, cuyas múltiples actividades revolucionarias le conceden un halo de ubicuidad, es decir, de presencia y ausencia simultánea. Su novia Iremita Johnson, de extracción congolesa y de nombre impronunciable para el sistema fónico de las lenguas occidentales, es la hija adoptada de un negro estadounidense, Ulises Johnson, onomástico éste indicador de su condición transcultural así como de un alto conformismo racial. Dino Calabrio es el falso nombre de Aristos Granadoupoulos, héroe antinazi que huye de la península helénica disfrazado de sacerdote ortodoxo, se instala en Sicilia como profesor de lenguas mediterráneas y termina por desembarcar en Nueva York donde se hace pasar como italiano exiliado. Moira Montrattis, doble de Juana Ribeiro Güin, nacida en Bolivia, es una cuñatai violada de joven por las fuerzas represivas de su país, quien después de pasar a los Estados Unidos con el alias de Mary Ariyaga se dedica a las actividades subversivas bajo la inadvertida protección de un pintor "constructivista", cuyo arte seudo-iconoclasta cae bajola estrategia del discurso hegemónico. Y suplementando la índole de "equívoco viviente" $(220)^{18}$ de este

\footnotetext{
${ }^{16}$ Por otra parte, en su ensayo crítico "Proust et les noms", Barthes lee el nombre propio como signo con poder de esencialización, citación y exploración, y cuyo espesor semántico es ámbito de significación que debe ser abierto al mundo:

Comme signe, le Nom propre s'offre à une exploration, à un dechiffrement: il est à la fois un 'milieu' ... dans lequel il faut se plonger, ... et un objet précieux, comprimé, embaumé, qu'il faut ouvrir comme une fleur". Nouveaux essais critiques (Paris: Editions du Seuil, 1972) 125.

${ }^{17}$ Empleo este término en sentido doble: como máscaras dramáticas y como concreción de fuerza actancial ("esfera de acción") en un relato, de acuerdo a A. J. Greimas, Semántica estructural. Trad. Alfredo de la Fuente (Madrid: Editorial Gredos S.A., 1971) 267.

${ }^{18}$ Comentando Cirlot en su Diccionario de simbolos (Barcelona: Editorial Labor, S.A., 1982) sobre el valor simbólico de "lo equívoco", anota que su acción tiende a la orgía, a la disrupcion saturnal del orden dado y a la posibilidad de uno nuevo; de ahf que el arte de los períodos equívocos exprese culturalmente la necesidad de invertir un estilo para transir a otro (185).
} 
complejo revolucionario, el relato incluye otro tipo de mascarada, el del travesti Tom Kress/Ann Couvert, quien, a pesar de no colaborar directamente en la lucha política, constituye una dislocación más radical del dictado social puesto que su ambivalencia sexual lo(la) saca "de su centro" (47) y la(lo) emblematiza como estrategia escandalizante de la propiedad psíquico-sexual.

El “¿Quién es quién?” (45) o juego carnavalesco inscrito en esta duplicidad de ropajes nominales acompaña entonces al entrecruzado sígnico y glósico como estrategia crítica del relato ante el conformismo incitado por el discurso del poder sobre el conjunto social y sus medios de expresión. Así, toda la madeja de informaciones contradictorias reunidas sobre el grupo subversivo por el aparato de investigación estatal es suministrado a la prensa como "un relato maravilloso perfectamente ecléctico al tamente integrado libre a primera vista de grandes contradicciones” (215). La función metalingüística de este enunciado nos hace reconocer el cifraje de la realidad y de la historia como disfraz retórico -leemos explícitamente que Moira Juanita Montrattis Ribeiro Güin, "artista genial, entiende que la realidad es lo mismo que la ficción" (220) - y confirma la tercera batalla crítica, ubicada a nivel de su propia praxis narrativa, librada contra la hegemonía de la pureza léxica y el acabado sintáctico del discurso representativo tradicional.

Es en este respecto que las propuestas bakhtianas sobre la relación entre la poliglosia y la naturaleza del género novelístico fundamentan de nuevo nuestra lectura. Según Bakhtin, la entrada de la antigüedad clásica europea en una economía de intercambio cultural y lingüístico constituyó la disrupción inicial del sordoaislamientoen que coexistían las naciones. El mundo monoglósico asociado con la ya mencionada ideología patriarcal y la figuración épica recibió de esta dinámica de interanimación etnocultural una apertura semántica que hubo de enfocar la consciencia creadora hacia un presente polivalente y problemático. ${ }^{19} \mathrm{El}$ distanciamiento jerárquico que había dominado la expresión literaria entró en retirada ante la nueva visión resultante de la actualización y del imbricamiento lingüístico. Fue la novela, como ámbito inconcluso e intercomunicativo, la que ofreció su potencialidad discursiva como mejor medio expresivo de la nueva visión multitonal: el proceso del constante dialogar se estableció así como la estructura fundamental de un género caracterizado por la carencia. ${ }^{20} \mathrm{Su}$ originalidad estilística, anota Bakhtin, aparece entonces íntimamente conectada con el fenómeno de la activa poliglosia internacional y del paralelo comercio ideológico en que entrara Europa en su momento clásico.

${ }^{10}$ Analizando el cerrado campo semántico del género épico, Bakhtin señala:

This absolute fusion and the consequent unfreedom of the subject was first overcome only with the arrival on the scene of an active polyglossia and interillumination of languages (and then the epic became a semiconventional, semimoribund genre) (17).

${ }^{20}$ Where languages and cultures interanimated each other, language became something entirely different; its very nature changed: in place of a single, unitary sealed-off Ptolemaic world of language, there appeared the open Galilean world of many languages, mutually animating each other (65). 
Por lo tanto, la apertura y dialogización del sujeto, implicadas como hemos visto en la temática del exilio neoyorquino, exige una actuación homóloga en el discurso novelístico que figura la historia. Es así que, como comentario metacrítico, la manifestación lingüística de Harlem todos los días se realiza desdoblando (hibridizando) sus componentes léxicos y rasgando (ofuscando) el encerramiento del hilado sintáctico normativo. A la ya mencionada contaminación del lenguaje -esencial en el cambio de Gerardo a Gerry, y experimentada igualmente por los otros exiliados, como en el archihegemónico abulense Manolo/Manny (215) y su criollo mesero Kenneth Rivera con su “abigarrado stock de zetas, jotas, ces, castizas" (131)—es necesario añadir el uso de la transformación morfológica encontrada en la economía lingüística del discurso. Efectuada en el desplazamiento entre diferentes sistemas fonológicos y dialectales, el nuevo contorno fonético de los significantes indica, para nuestra lectura, la maleabilidad del sistema y la coparticipación en las formas expresivas. Así, el "absurdo trabalenguas" de "Erre con erre cigarro / erre con erre barril / rápido corren los carros / detrás del ferrocarril" es exorcizado de su hermetismo épico con la "fonética más meliflua y civilizada" de "Ele con ele cigalo / ele con ele balil/lápilo colen los calos / detlás del felocalil" (33). Por su parte, el trenzado lineal narrativo se materializa inestablemente en base al uso recurrente de tres figuras retóricas que sobresaltan y sobreasaltan la propiedad del curso sintáctico: el asíndeton, la enumeración paradigmática y el oxímoron, las tres contribuyendo de igual manera al "mundo trenzado de manera poco discursiva" experimentado por Gerardo. La autoconciencia narrativa de esta estrategia crítica deconstructora es claramente anunciada por la voz enunciadora instalada en el pensamiento de Aleluya:

Intuy6 que en cada diálogo existen empates defectuosos, hilos sueltos, corrientes que escapan sigilosamente y se pierden en la nada y recargan la atmosfera con una tensión que si bien no se percibe claramente, no deja de pesar sobre cada persona, contaminación indefinible como cuando se corrige mal la fractura de un hueso que no queda debidamente soldado: prevalecen secretas dolamas debidas a esa conexión defectuosa (¿realmente lamentable, no?). O como cuando un chorro perfecto, de rasgos bien definidos, que avanza configurado por un tubo, deja escapar a través de una mínima fisura unas hilachas: la tubularidad esperada redondamente en el conjunto se echa a perder, se traba el ritmo, surge un breve trauma registrable quien sabe en que contexto misterioso (65-6).

El cariz teórico de este enunciado desnuda la funcionalidad centrífuga y explosiva del marcado insistir asindético encontrado a lo largo del relato-bien visto en "La señora Parker los toma en brazos, gorda amorosa papada asegurada en un cuarto de millón de dólares. Brazos tintinean cuello rebrilla joyas sedas sobre su pecho gordo" (106)-y del frecuente listado arbitrario y antijerárquico de vocablos inconexos que, como espacio de tesoro mnemónico, facilita la concurrencia asociativa de términos en ausencia: 


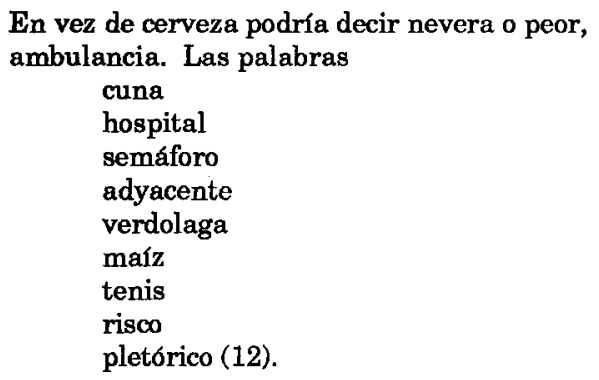

Mientras que ambos recursos retóricos establecen ranuras intersegmentales que tornan poroso el bloque del discurso, el antitético encuentro facilitado por las atracciones oximorónicas de semas y etnias (25-34) divergentes permiten en el lugar de la escritura la "mera y necesaria convivencia pacífica" (33) de una heterofonia creativa:

Plantas, minerales, animales de todas clases debian ser, minuciosamente mordidas (sic), chupados, demolidos, masticados, exterminados, deglutidos, con un peninsular odio alegrísimo, sometiendo las románticas quijadas a aventuras quijotescas del apetito, termitas ligeramente cristianas, el mundo es un banquete rediez (130).

El trabajo de fisura en la palabra monolítica así anunciado encuentra, por otra parte, un correlato narrativo de funcionalidad también metacrítica en el motivo de la música. ${ }^{21}$ De la misma manera que la "palabrafogata" (101) que estalla en el yo plural de la cópula Gerry-Caty menoscaba la palabra-piedra del yo monal de Gerardo, la "jodida música dislocada" (98) de la sensibilidad harlemniana erige su polivalencia intersticial contra la disciplina de todo acabado melódico:

El ritmo de Mongo es lento pero cargado ... y el pacumpá pacumpá del principio se disuelve en un cucumpá más relajado y soportable cómodo y sobre ruedas. $\mathrm{La}$ trompeta y el saxo parecen obedecer con alarmante dogmatismo lo escrito y fijado mortalmente en el pentagrama, aunque Bigote nota perspicazmente que aquí y allá la trompeta deja escapar algún gemido anarquizante. Con clara permanencia a lo largo del número, espontánea y descuidadamente lumpeniano, el coro le agrega naturalidad desafiante, cierta marihuanidad al conjunto ... No le molesta en realidad Tito Puente, pero reconoce que resulta ya un tanto pasado con su gran banda tan meditada, sus movimientos calculados y perfectos, enquistados en un formalismo que niega toda apertura dinámica (14-5).

${ }^{21}$ Similarmente, el motivo de los alucinogénicos (marihuana), y los topos del amor y del sueño, connotados los tres como elementos que liberan de la autoridad, forman parte del heterocosmos narrativo. Los límites de este estudio no permiten considerarlos en detalle. 
Es en este aspecto donde la simpatía del narrador hacia el relativismo dinámico del ritmoabierto engarza comoalusión intertextual con la promulgación cortazariana de la inconclusividad formal del jazz y su aplicabilidad en el desarrollo de una nueva forma novelística anticausal y dialógica. ${ }^{22}$

Si este proyecto deshegemonizante en base a la interanimación dialógica del exilio se inscribe, como hemos visto, en diferentes planos de manifestación textual, debe necesariamente efectuarse en el plano del narrador mismo, y en última instancia, en el del sujeto responsable de la inscripción para ser adecuadamente fiel a su propósito. La contaminación del habla de la voz enunciadora es un fenómeno distinguible que va intensificándose a medida que Gerardo entra en contacto con la pluralidad glósica y dialectal de los coexiliados. Con ello la distancia que a comienzos del relato separa las entidades de los sujetos enunciador y enunciado pierde toda credibilidad: leemos que la ya híbrida zona de voz de "Gerry el Pensativo Nostálgico", quien argentinamente decide llorar "a pesar de que los ombres no deben yorar ... un ombre massho no debe shorar", se injerta a la de su enunciante en la doble focalización de "hay palabras que se agotan, desfallecen, se desploman muertas de debilidad y exhalan el último suspiro, es decir hasta boquean y todo, tú sabes, pero que you know hay otras que anyway prevalecen como huellas de carimbo" (97); y a su vez, la instancia emisora del relato canibaliza su objeto en la incorporación del característico lambadaísmo puertorriqueño, "(para mental un mal menol entre tantos)" (179). El cifraje a "doble voz" que según Bakhtin conforma la especificidad del género novelístico y lo define como sistema de lenguajes de mutua interanimación ideológica queda explícitamente manifestado en esta zona conjuntiva del texto de Diaz Valcárcel..$^{23}$

Esta mención del nombre autorial nos lleva a su consideración como punto de originación del relato. La íntima relación que como he anotado se establece entre Gerardo y la voz narrativa por medio del contagio lingüístico se extiende a la instancia del autor implícito con la aparición al final del relato del escritor puertorriqueño Zaid Lecráclav, inscripción bustrófedon de Díaz Valcárcel, quien, como personaje de ficción refleja la llegada del autor empírico a Nueva York con la intención de escribir un libro sobre la vida de sus compatriotas exiliados en esta ciudad. En las reuniones en casa de Gerry y Caty, el propio

${ }_{22}$ Cito, como ejemplo entre muchos posibles, de La vuelta al día en ochenta mundos

(México: Siglo Veintiuno Editores, S.A., 1967):

Sucede además que por el jazz salgo siempre a lo abierto, me libro del cangrejo de lo idéntico para ganar esponja y simultaneidad porosa, una participación que en esa noche de Lester era un ir y venir de pedazos de estrellas, de anagramas y palindromas (7).

${ }^{23}$ En los comentarios sobre la habilidad del lenguaje del narrador no épico, es decir novelístico, de representar otro lenguaje reteniendola capacidad de sonar simultáneamente fuera y dentro de éste, anota Bakhtin: "Thus, there are always two consciousness, two language intentions, two voices and consequently two accents participating in an intentional and conscious artistic hybrid (360). 
Gerry le narra a Zaíd sus experiencias de los últimos nueve meses que son naturalmente los eventos que habíamos leído hasta ese momento y que, a la misma vez, constituye el relato de la novela que Zaíd Lecráclav/Díaz Valcárcel concluye al terminar la narración y despedirse de "su querido Gerry" (229). Cuanto que la voz narrativa que da comienzo a la ficción narra la vida de Gerardo y éste, recíprocamente, le narra a Zaíd —cifraje inverso de la instancia autorial- los acontecimientos ya leídos, es decir, el discurso de Harlem todos los días, el efecto resultante es un circular juego espejeante que dialogiza la zona de propiedad del inscriptor. Con ello se efectúa, como señala Bakhtin con respecto a los diálogos socráticos, la incorporación del autor dentro del cosmos narrado en una zona de contacto dialógico ${ }^{24}$ y su participación en el equívoco carnavalesco jugado por sus criaturas de ficción. ${ }^{25}$

La intencionalidad desdoblante está igualmente sugerida por el índice del texto. Por un lado, el número de dieciocho secciones narrativas en las que se divide el discurso es el múltiple doble de nueve, es decir, del lapso de gestación necesario para el parto duple inscrito en el relato como provocación del exilio: Díaz Valcárcel comienza a escribir su novela en Nueva York y la continúa en Madrid; Gerardo se queda en la Urbe "soñando a veces con volvel cuanto llevo aquí nueve meses toda la vida ya mismo paro" (226) (énfasis mío). Y, por otro lado, la "titulación" o "entradas" en el índice de lo que corresponde a cada capítulo consiste en el sintagma inicial que nos da la entrada al cuerpo de cada sección discursiva. Así, el proceso de lectura es reinstaurado doble y circularmente a su comienzo, paralelizandoel acto narrativo dialógico de Gerry/voz enunciadora/ Zaíd y negando el acabamiento de la textualidad.

Lo que está implicado en esta meditación sobre la propia forma representacional de la novela, mano a mano el planteamiento temático de la contaminación exílica del sujeto y su lenguaje, es una posibilidad de desestabilización más viable $\mathrm{y}$, a la larga, más efectiva como mecanismo de cambio de la hegemonía mantenida por los mitos de un lenguaje social unitario. A medida que los medios instantáneos de comunicación de nuestro momento postindustrial transformen, como indicara McLuhan, nuestras sociedades aisladas en una villa global $-y$ "exílica”, en la dimensión de contacto con la otredad que se hace nuestra-, volverá a efectuarse otra reorientación radical en nuestra concepción de la realidad y se gestarán nuevos sistemas de representación más adecuados a la libertad del complejo pensamiento humano y de su siempre inacabado proyecto, tal como ocurriera con la interanimación

\footnotetext{
24 "The hero is located in a zone of potential conversation with the author, in a zone of dialogical contact" (45).

${ }^{26}$ Cuanto al estructuramiento artístico en base a la tradición de mascarada popular y su esencial contribución al género de la novela indica Bakhtin:

These masks and their structure (the noncoincidence with themselves, and with any given situation - the surplus, the inexhaustibility of their self and the like), have had, we repeat, an enormous influence on the development of the novelistic image of man (36-7).
} 
lingüístico-cultural de la Europa clásica. Una vez dado ese momento, Harlem todos los días será leído más enfocadamente como un temprano auspicio e iniciación de un "hombre nuevo" en una sociedad universalmente abierta. En el contexto de la novelística de Díaz Valcárcel, este texto continúa la empresa de hacer el modo de literatura "revolucionaria" que, en Figuraciones en el mes de marzo, logró un reconocido valor estético. Sin embargo, el evidente pesimismo presente en la protesta catatónica del intelectual exiliado Eddy Leiseca -que como indicara Randolph Pope constituye un modelo de "contestación" que no llega al plano de la acción como positividad ${ }^{26}$ - es abandonado en favor de la fiesta de la palabra carnavalesca de los actores de Harlem, espectáculo de comercio ilegítimo, resistente y convocador a la vez, en el sitio primordial de la sociedad, el lugar del habla.

Cuando en la entrevista con el exiliado judío Jeremías Guzmanski, abogado de los litigios de Aleluya, éste le dice en pretenso español sefardí que "New York est la nuova Babel, mais aqueste odren peregrino nos debemoss embertir" (86), la inversión del nombre del poder autorial - "Zaíd Lecráclav" - se torna en indicio de que, para poder impostar pluralmente la monotonía de las formas restrictivas, la estrategia de enfrentamiento no puede ocupar una posición de exterioridad al conjunto de relaciones que forman la red hegemónica, sino que tiene que necesariamente comenzar en el espacio común que las posibilita, es decir, en el del lenguaje. Si Aleluya y sus correvolucionarios desaparecen "como tragados por la tierra" (223), y la praxis subversiva directa que ellos intentan queda silenciada en el suspenso ruidoso del texto harlemniano, la indirecta labor disruptora de la economía interglósica del exilio mantiene su operatividad en el ruido silencioso de Harlem todos los días. En este espacio textual de copulación cultural y de contaminación lingüística, el ser humano se exilia de la propiedad del nombre para incorporar la onomasis del exilio: hallelujah, imperativo plural de coparticipación.

${ }^{26}$ Randolph D. Pope, "Dos novelas álbum: Libro de Manuel de Cortázar y Figuraciones en el mes de marzo de Díaz Valcárcel”. La Revista Bilingüe 2 (May-August 1974) 17084 . 
